\title{
Expression and Tissue Localization of Membrane-Types 1, 2, and 3 Matrix Metalloproteinases in Rheumatoid Synovium
}

\author{
Hajime Yamanaka, Ken-ichi Makino, Masayuki Takizawa, Hiroyuki Nakamura, \\ Noboru Fujimoto, Hideshige Moriya, Ryoichi Nemori, Hiroshi Sato, Motoharu Seiki, \\ and Yasunori Okada
}

Department of Pathology (HY, KM, MT, HN, YO), School of Medicine, Keio University, Fuji Photo Film Co., Ltd. (RN), and Department of Cancer Cell Research (MS), Institute of Medical Science, University of Tokyo, Tokyo, Department of Orthopaedic Surgery (HY, HM), School of Medicine, Chiba University, Chiba, Biopharmaceutical Department (NF), Fuji Chemical Industries, Ltd., Takaoka, and Department of Virology and Oncology (HS), Cancer Research Institute, Kanazawa University, Kanazawa; Japan

\begin{abstract}
SUMMARY: In vitro, membrane-type matrix metalloproteinases (MT-MMP) are known to activate the zymogen of MMP-2 (proMMP-2, progelatinase A), which is one of the key MMP in joint destruction in rheumatoid arthritis. In the present study, we examined the production and activation of proMMP-2, and the expression of MT1-MMP, MT2-MMP, and MT3-MMP, their correlation with proMMP-2 activation, and their localization in rheumatoid synovial tissue. Using sandwich enzyme immunoassay and gelatin zymography techniques, proMMP-2 production levels and activation ratios were found to be significantly higher in rheumatoid synovium compared with normal synovium $(p<0.01)$. Quantitative RT-PCR analyses demonstrated that MT1-MMP and MT3-MMP were expressed in all rheumatoid synovial tissue (30 of 30 cases), but that the mean expression level of MT1-MMP was approximately 11-fold higher than MT3-MMP. Significant correlation was found between the mRNA expression level of MT1-MMP and the activation ratio of proMMP-2 $(p<0.01)$. In situ hybridization indicated that the hyperplastic lining cells of rheumatoid synovium expressed MT1-MMP. Immunohistochemistry demonstrated that MT1-MMP was co-localized with MMP-2 and with a tissue inhibitor of metalloproteinase-2, and was mainly located in the rheumatoid synovial lining cells. In situ zymography of rheumatoid synovium showed gelatinolytic activity, predominantly in the lining cell layer. This activity was blocked when incubated with BB94, a specific MMP inhibitor. These results demonstrate that MT1-MMP plays an important role in the activation of proMMP-2 in the rheumatoid synovial lining cell layer, and suggest that its activity may be involved in the cartilage destruction of rheumatoid arthritis. (Lab Invest 2000, 80:677-687).
\end{abstract}

$I$ $n$ rheumatoid arthritis (RA), the affected joints show chronic proliferative synovitis that is implicated in the destruction of articular cartilage and subchondral bones, resulting in disability of the joints. Proteolytic degradation of the extracellular matrix (ECM) of the cartilage is a key step in joint destruction of RA (Okada, 2000). Although various proteinases are involved in the process, matrix metalloproteinases (MMP), a gene family of zinc metalloproteinases that can degrade ECM components, are believed to play a major role in the degradation of the cartilage ECM (Nagase and Woessner, 1993; Okada, 2000). Among MMP, MMP-2 (gelatinase A) may be especially important in collagen degradation, through digestion of

Received December 10, 1999.

Supported by a Grant-in-Aid from the Ministry of Education, Science, and Culture of Japan, Health Sciences Research Grants from the Ministry of Health and Welfare of Japan, and a Keio University Special Grant-in-Aid for Innovative Collaborative Research Projects (to YO).

Address reprint requests to: Dr. Y. Okada, Department of Pathology, School of Medicine, Keio University, 35 Shinanomachi, Shinjuku-ku, Tokyo 160-0016, Japan. Fax: 8133353 3290; E-mail: okada@med.keio.ac.jp gelatins generated by thermal denaturation at body temperature after the specific cleavage of the triple helical region of the fibrillar collagen molecules by collagenases (Okada, 2000). MMP-2 also digests other substrates including aggrecan, link protein, decorin, and type $\mathrm{X}$ and $\mathrm{XI}$ collagens, all components of the articular cartilage matrix (Fosang et al, 1992; Imai et al, 1997a; 1997b; Nguyen et al, 1993; Okada, 2000; Okada et al, 1990). However, overexpression is not sufficient for the in vivo action of MMP-2, because, like other MMP, MMP-2 is secreted as an inactive zymogen (proMMP-2). Thus, activation is a prerequisite to its functioning in vivo. Various factors such as organomercurials, serine proteinases, hypochlorous acid, and acid exposure are known to activate proMMP in vitro, and serine proteinases including plasmin, plasma kallikrein, and neutrophil elastase may be important in vivo activators for proMMP (Nagase, 1997). However, proMMP-2 is unique in that it is not activated by serine proteinases (Okada et al, 1990), but activated by membrane-type (MT) MMP, a family with five different known members, MT1-MMP (Sato et al, 1994), MT2-MMP (Will and Hinzmann, 
1995), MT3-MMP (Takino et al, 1995), MT4-MMP (Puente et al, 1996), and MT5-MMP (Pei, 1999). MT5MMP is a recently discovered MT-MMP, and its expression seems to be limited to brain tissues (Pei, 1999) and brain tumors (Llano et al, 1999). MT4-MMP differs from other members of the MT-MMP subgroup because it is a glycosylphosphatidylinositol-anchored enzyme without a transmembrane domain (Itoh et al, 1999). The proMMP-2 activator function of MT4-MMP is questionable because the purified recombinant catalytic domain did not activate proMMP-2 in one study (Kolkenbrock et al, 1999), but did activate proMMP-2 in another study (Wang et al, 1999). When COS1 cells were co-transfected with expression plasmids for MT4-MMP and MMP-2, no activation of proMMP-2 was observed ( $\mathrm{Y}$ Itoh and $\mathrm{M}$ Seiki, unpublished observations). However, involvement of MT1-MMP and/or MT2-MMP in proMMP-2 activation has been reported in many human carcinoma tissues (Nakada et al, 1999; Nakamura et al, 1999; Nomura et al, 1995; Tsunezuka et al, 1996; Ueno et al, 1997). Recent studies also show expression of MT1-MMP in cartilage of osteoarthritis (OA) (Buttner et al, 1997; Imai et al, 1997a; 1997b), in synovial tissues of RA, and in traumatic joints (Konttinen et al, 1998). However, nothing is known about proMMP-2 production levels, the activation of proMMP-2 in RA synovial tissue, or MT-MMP species involved in proMMP-2 activation. In addition, tissue localization of activated MMP-2 has not been studied in RA synovial tissues.

In this study, we examined the production and activation of proMMP-2; the expression of MT1-MMP, MT2-MMP, and MT3-MMP; the correlation between MT-MMP expression and proMMP-2 activation; the tissue localization of MMP; and the gelatinolytic activity of proMMP-2 in RA synovial tissue. Our results suggest that overproduced proMMP-2 is activated by MT1-MMP and that the activity is localized to the lining cell layer of RA synovium.

A

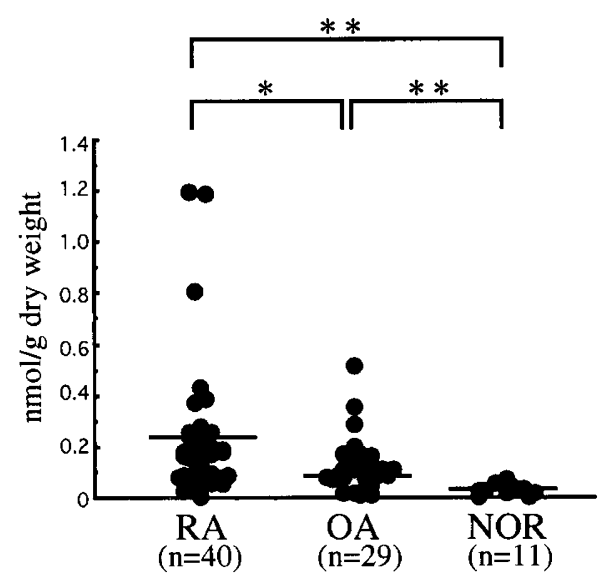

\section{Results}

\section{Production of ProMMP-2 in Synovial Tissues}

To measure the amounts of proMMP-2 produced by RA, OA, and normal synovial tissues, the sandwich enzyme immunoassay (EIA) system was used with culture media and homogenate supernatants of the synovium. As shown in Figure 1A, the production level of proMMP-2 in the culture media of RA synovium $(0.228 \pm 0.262 \mathrm{nmol} / \mathrm{g}$ dry weight, mean $\pm \mathrm{SD}, n=40)$ was remarkably higher than the level in OA $(0.135 \pm$ $0.104 \mathrm{nmol} / \mathrm{g}$ dry weight, $n=29)$, or normal synovium $(0.029 \pm 0.019 \mathrm{nmol} / \mathrm{g}$ dry weight, $n=11)(p<0.05$ and $p<0.01$, respectively). Similarly, the proMMP-2 production level in homogenates of RA synovium $(0.432 \pm 0.192 \mathrm{nmol} / \mathrm{g}$ of protein, $n=40)$ was significantly higher than the level in normal synovial samples $(0.085 \pm 0.065 \mathrm{nmol} / \mathrm{g}$ of protein, $n=11, p<$ $0.01)$, although the levels were not significantly different between RA and OA $(0.405 \pm 0.216 \mathrm{nmol} / \mathrm{g}$ of protein, $n=29$ ) (Fig. 1B).

\section{Activation of ProMMP-2}

ProMMP-2 activation in the culture media and homogenate supernatants was analyzed by gelatin zymography. The 68-kd proMMP-2 form was detected in all examined culture media, with higher levels in RA than in OA or normal samples (Fig. 2A), confirming the EIA data. The active species of $62 \mathrm{kd}$ was detected in most samples, but the proteolytic band was broader in RA than in OA or normal synovial samples (Fig. 2A). Similar results were obtained with the homogenate supernatants (data not shown). Computer-assisted image analyses of the proteolytic bands showed that the activation ratio (the ratio of the 62-kd active form to the proMMP-2 form plus the active form) in the culture media is significantly higher in $\mathrm{RA}(0.40 \pm 0.18$, $n=40)$ than in OA $(0.20 \pm 0.11, n=29)$ and normal

\section{$\mathrm{B}$}

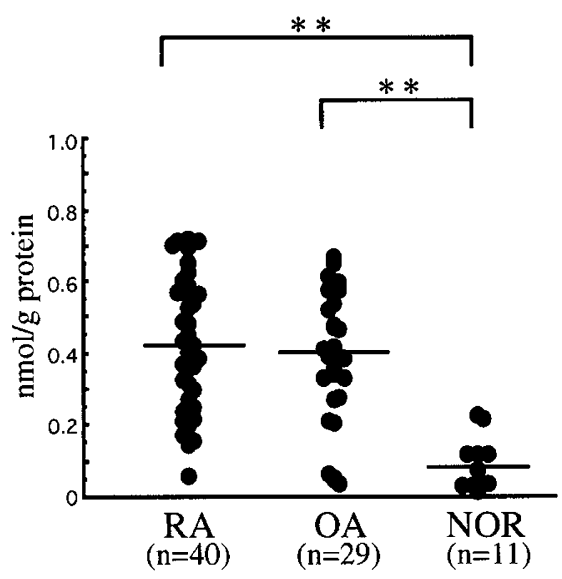

Figure 1.

Amounts of the zymogen of matrix metalloproteinase (MMP)-2 (proMMP-2) in the conditioned media $(A)$ and the tissue homogenates (B) of rheumatoid arthritis $(R A)$, osteoarthritis $(O A)$, and normal $(N O R)$ synovium. Conditioned media and homogenates were prepared from synovial tissues, and proMMP-2 was measured by the sandwich enzyme immunoassay (EIA) system. Values (nmol/g dry weight for culture media and $\mathrm{nmol} / \mathrm{g}$ protein for homogenates) were calculated as described in "Materials and Methods." Bars indicate the mean value. ${ }^{\star}, p<0.05 ;{ }^{\star \star}, p<0.01$. 
A

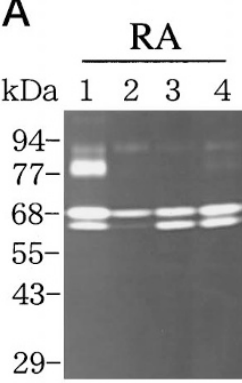

$\mathrm{OA}$

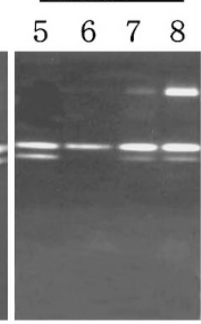

NOR
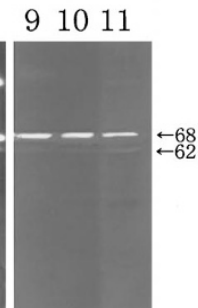

B

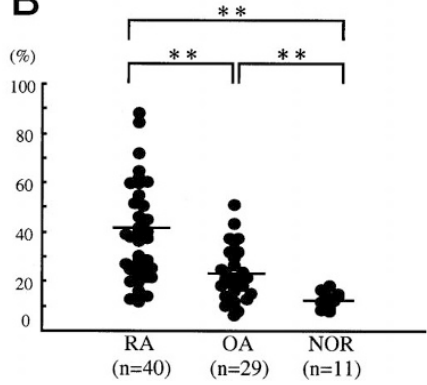

C

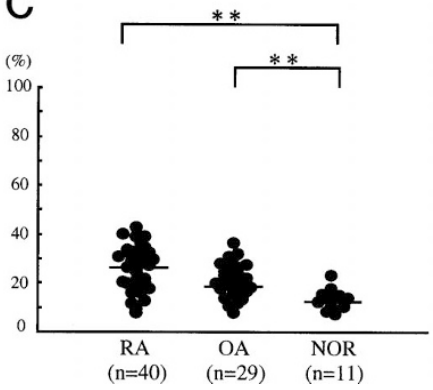

Figure 2.

Analysis of the activation of proMMP-2 by gelatin zymography. A, Gelatin zymography. The conditioned media from RA (lanes 1 to 4 ), OA (lanes 5 to 8 ), and normal (NOR) synovium (lanes 9 to 11) were subjected to gelatin zymography as described in "Materials and Methods". Major gelatinolytic bands of 68 kd and 62 kd, which correspond to proMMP-2 and active MMP-2, respectively, are indicated. B and C, Activation ratios of proMMP-2 in the conditioned media (B) and tissue homogenates (C). The activation ratios (\%) were measured by a computer-assisted densitometric analysis of the gels as described in "Materials and Methods." Bars indicate the mean value. ${ }^{\star *}, p<0.01$.

synovial samples $(0.13 \pm 0.04, n=11)(p<0.01$ and $p<0.01$, respectively) (Fig. 2B). The activation ratio was also significantly higher in RA tissue homogenates $(0.24 \pm 0.09, n=40)$ than in normal samples $(0.11 \pm 0.04, n=11)(p<0.01)$, but the ratio was not different between RA and OA $(0.17 \pm 0.09, n=29)$ samples (Fig. 2C).

\section{MT1-MMP, MT2-MMP, and MT3-MMP mRNA Expression}

When RT-PCR for MT-MMP was carried out with total RNA from synovial tissues, MT1-MMP mRNA was detected in $100 \%$ of the RA and OA synovial samples (30 of 30 and 14 of 14 cases, respectively), but was detectable in only $25 \%$ of the normal synovium (2 of 8 cases) (Fig. 3). MT3-MMP was also expressed in $100 \%$ of the RA synovium (30 of 30 cases) and in $86 \%$ of the OA synovium (12 of 14 cases), whereas it was undetectable in the normal synovium (0 of 8 cases) (Fig. 3). MT2-MMP mRNA was not found in any of the synovial tissues examined (Fig. 3).

To evaluate the expression levels of MT1-MMP and MT3-MMP, quantitative analyses of the mRNA expression of MT-MMP and glyceraldehyde-3-phosphate dehydrogenase (GAPDH) were performed, and the levels (ratio of MT-MMP to GAPDH) were calculated according to the methods reported in our recent study (Nakada et al, 1999). The level of MT1-MMP was significantly higher in the RA synovial samples $(4.35 \pm 5.32, n=30)$ than in the normal synovium $(0.55 \pm 0.89, n=8 ; p<0.01$ ) (Fig. $4 A)$. Although the level in the OA synovial samples (3.01 $\pm 2.57, n=14$ ) was higher than in the normal synovium, it was not significantly different from level in the RA synovial samples. Similar expression patterns of MT3-MMP were obtained: the expression level in RA synovial samples $(0.39 \pm 0.44, n=30)$ was significantly higher than that in the normal samples $(0.02 \pm 0.04, n=$ 8), but the level was not different from that in OA samples $(0.26 \pm 0.41, n=14)$ (Fig. 4B). When the mean expression levels of these MT-MMP were compared, the MT3MMP level was approximately 11-fold lower than MT1MMP. The expression levels of MT1-MMP correlated with scores of synovial lining cell hyperplasia in the RA synovium ( $r=0.705, n=30$ ), but did not correlate with the total scores, or with the scores of inflammatory cell infiltration and fibrosis (not shown).

\section{Correlation Between ProMMP-2 Activation and Expression of MT1-MMP and MT3-MMP}

When the mRNA expression level of MT1-MMP was plotted against the activation ratio of proMMP-2 in each RA sample, there were direct correlations in both the culture media $(r=0.753, p<0.01)$ and the homogenates $(r=0.769, p<0.01)$ (Fig. 5, A and B). A weak correlation was also found between MT3-MMP

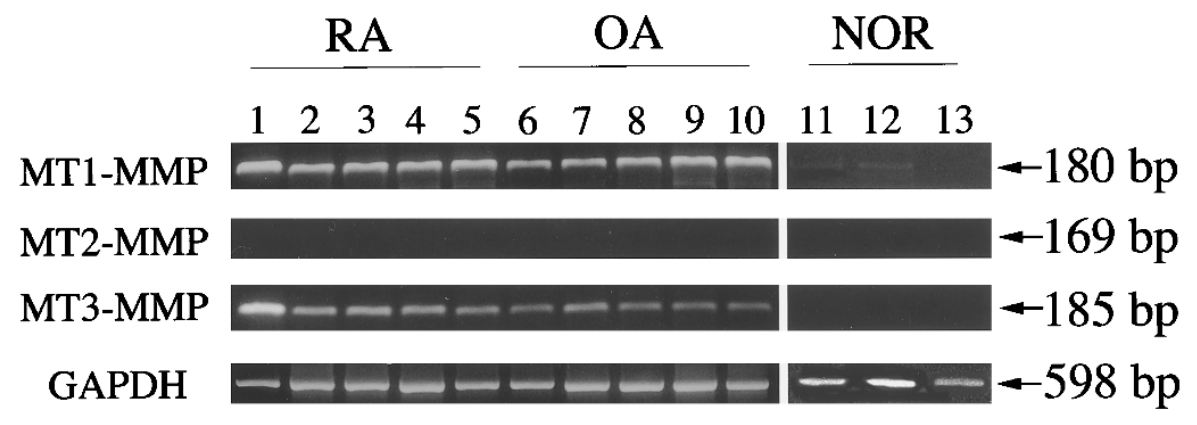

Figure 3.

Determination of mRNA expression of membrane-type (MT)1-MMP, MT2-MMP, MT3-MMP, and GAPDH in RA, OA, and NOR synovium by RT-PCR. Total RNA was extracted from RA, OA, and NOR synovium, and reverse-transcribed into cDNA followed by PCR reaction at 30 cycles. Representative samples of RA (five cases, lanes 1 to 5), OA (five cases, lanes 6 to 10) and NOR (three cases, lanes 11 to 13) synovium are shown. Molecular sizes of the PCR products are indicated. 

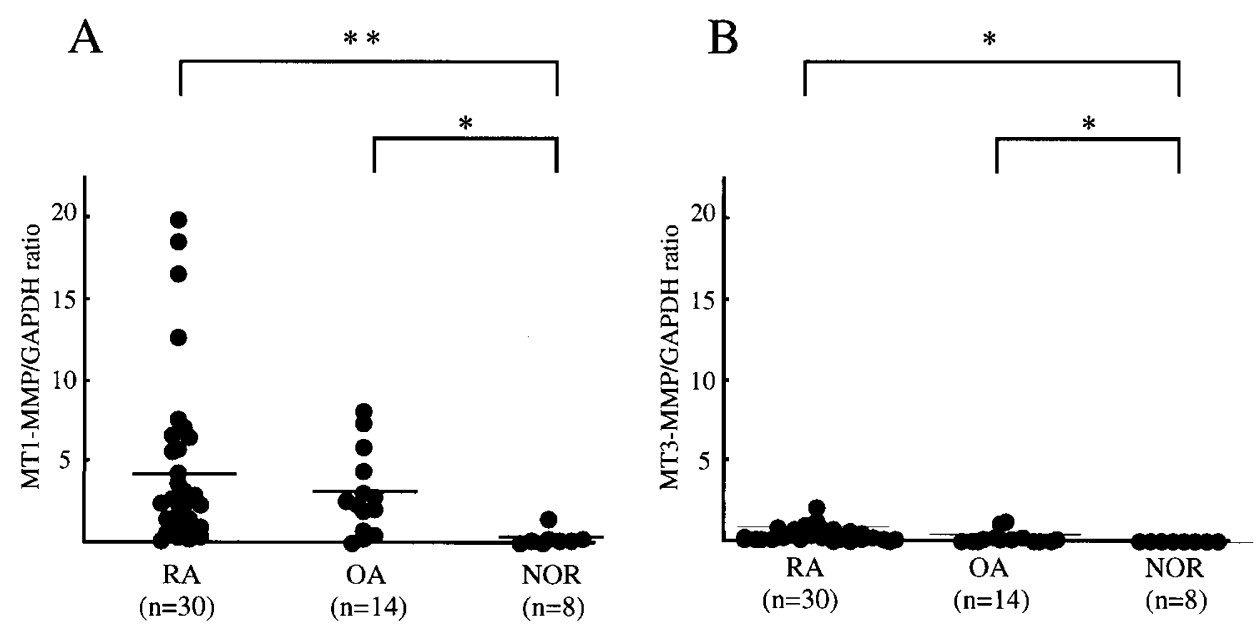

Figure 4.

The mRNA expression levels of MT1-MMP and MT3-MMP in RA, OA, and NOR synovium. The relative mRNA expression levels (MT-MMP/GAPDH ratios) were determined by the quantitative RT-PCR method as described in "Materials and Methods". Bars indicate the mean value. ${ }^{*}, p<0.05 ;{ }^{* *}, p<0.01$.

A

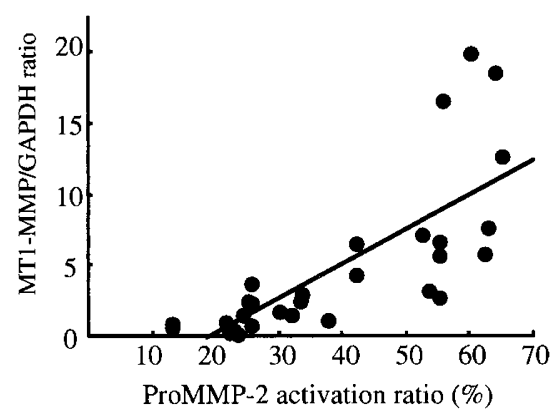

B

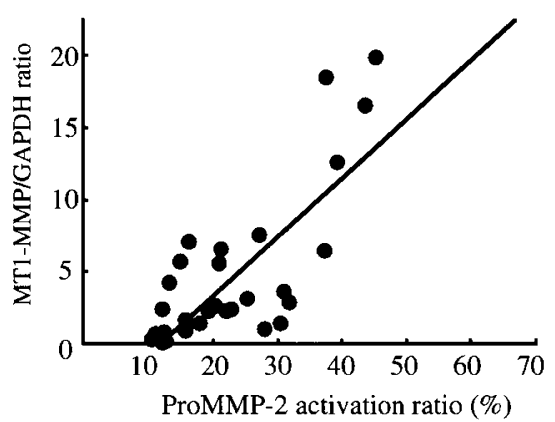

\section{Figure 5.}

The correlation between the mRNA expression level of MT1-MMP and the proMMP-2 activation ratio in conditioned media $(A)$ and homogenate supernatants (B) of RA synovium. Direct correlations are observed with correlation coefficients of $r=0.753(p<0.01)$ for culture media, and $r=0.769(p<0.01)$ for homogenate supernatants.

expression and proMMP-2 activation in the culture media $(r=0.393, p<0.05)$ and the homogenates $(r=$ $0.445, p<0.05$ ) (not shown).

\section{In Situ Hybridization}

Cells expressing MT1-MMP mRNA in RA synovial tissue were identified by in situ hybridization. Strong signals for MT1-MMP were predominantly observed in synovial lining cells with an anti-sense RNA probe (nine of nine cases), whereas the sense probe showed only a background signal in the tissue (Fig. 6, A and B). Although MT3-MMP-expressing cells in the RA synovium were also examined with an anti-sense probe, no definite signals were found, probably because of the low mRNA expression level (not shown).

\section{Immunohistochemistry and Immunoblotting}

MT1-MMP was predominantly immunolocalized to hyperplastic synovial lining cells in $83 \%$ of the RA synovial samples (25 of 30 cases) (Fig. 6C). Endothelial cells of blood vessels in RA synovial tissue were occasionally immunoreactive for MT1-MMP (not shown). MMP-2 and tissue inhibitor of metalloproteinases-2 (TIMP-2) expressions were also localized to RA synovial lining cells and fibroblasts in the sublining cell layer (Fig. 6, D and E), although MMP-2 immunoreactivity was mainly seen on the cell membranes of the lining cells. No immunoreactivity was observed with non-immune mouse lgG (Fig. 6F).

By immunoblotting, both the latent and active forms of MT1-MMP (66 kd and $60 \mathrm{kd}$, respectively) were identified in tissue homogenates of RA synovial samples, but neither form was present in normal synovial samples (Fig. 7).

\section{Detection of Gelatinolytic Activity by In Situ Zymography}

In situ zymography using gelatin films demonstrated gelatinolytic activity in the lining cell layer of RA synovial tissue after a short incubation (4 hours) (Fig. $8, A$ and B). However, most areas of the RA synovium showed activity after a longer incubation period (12 hours) (Fig. $8 \mathrm{C}$ ), but no activity was recognized in 

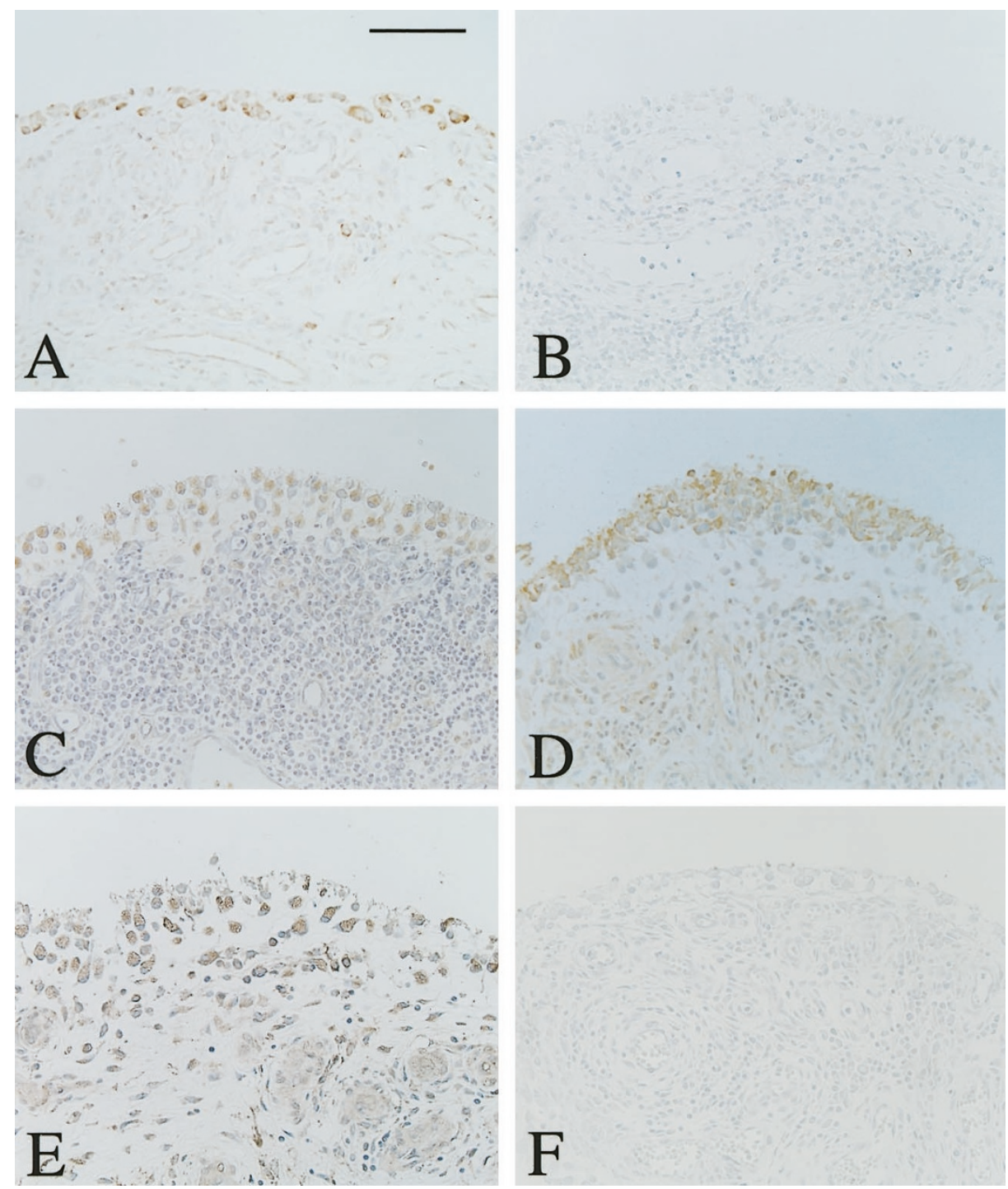

\section{Figure 6.}

In situ hybridization for MT1-MMP and immunolocalization of MT1-MMP, MMP-2, and TIMP-2 in RA synovium. A and B, In situ hybridization. In situ hybridization was performed with the anti-sense probe (A) or the sense probe (B) in the RA synovium as described in "Materials and Methods." Note the intense labeling in the lining cells with the antisense probe. C, D, E, and F, Immunohistochemistry. Paraffin sections were immunoreacted with monoclonal antibodies to MT1-MMP (C), MMP-2 (D), and TIMP-2 (E), or with non-immune mouse $\operatorname{lgG}(\mathrm{F})$ as described in "Materials and Methods". Note the immunolocalization of MT1-MMP, MMP-2, and TIMP-2 to the lining cells, whereas no immunoreactivity is observed with non-immune mouse lgG. Hematoxylin counterstaining. Bar, $50 \mu \mathrm{m}$.

normal synovial tissue (not shown). This activity was almost completely blocked in RA synovial tissue that was incubated with BB94, a synthetic MMP inhibitor (Fig. 8, D, E, and F). The distribution of activity in the lining cell layer was consistent with the immunolocalization of MT1-MMP, MMP-2, and TIMP-2.

\section{Discussion}

RA synovial fibroblasts in culture produce and secrete proMMP-2 into the media (Okada et al, 1990), and the production of proMMP-2 in RA synovial tissue has been shown by immunohistochemistry (Hembry et al, 1995; Konttinen et al, 1998). However, no reports have described the production levels of MMP-2 in RA, OA, and normal synovial tissues. In the present study, we have demonstrated that proMMP-2 production levels in RA synovial tissue are significantly higher (5-fold to 8 -fold) than the levels in normal synovium. Because the level in the culture media of RA synovium was also significantly higher than the level in OA synovial media, RA synovium seemed to produce proMMP-2 more rapidly than OA synovial tissue. However, our immunohistochemical study showed that MMP-2 is mainly localized to the cell membranes of the synovial lining cells and within the fibroblasts in the sublining cell layer. This localization could explain the discrepancy between the secreted levels whereas the homogenate levels were comparable, and suggests that a similar amount of proMMP-2 was trapped in both RA and OA synovial tissues.

One of the most interesting findings in this study is that proMMP-2 was activated in RA synovium. The 


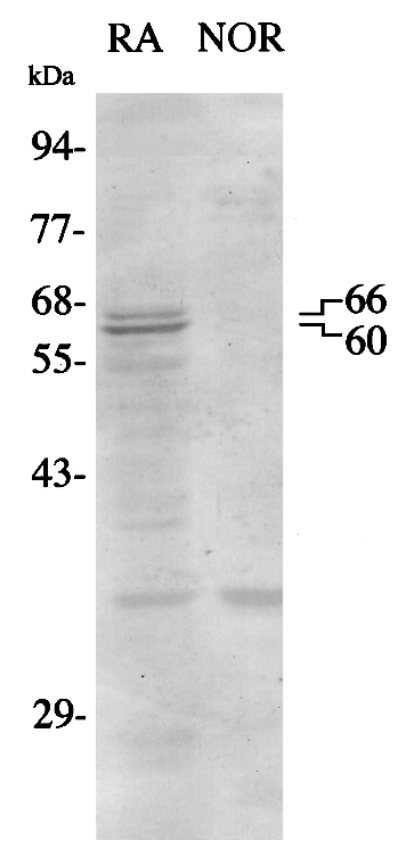

Figure 7.

Immunoblotting for MT1-MMP. Tissue homogenates from RA and NOR synovium were resolved by SDS-PAGE, transferred onto nitrocellulose filters, and immunoreacted with the antibody to MT1-MMP. Note that two bands corresponding to latent and active forms of MT1-MMP are found in the RA sample, whereas no such species are detected in the NOR sample.

activation ratio of proMMP-2 in the culture media of RA synovium was significantly higher than that in $\mathrm{OA}$ or normal synovium, whereas the ratio was not different between the homogenates of the RA and OA synovial tissues. This suggests that proMMP-2 is efficiently activated in RA synovium, and that activated MMP-2 is readily secreted into the media from the tissue. Because MT1-MMP, MT2-MMP, and MT3MMP are believed to be tissue activators of proMMP-2 (Okada, 2000 ; Sato et al, 1994; Takino et al, 1995; Will and Hinzmann, 1995), we initially examined their gene expression in the synovium by RTPCR. Although both MT1-MMP and MT3-MMP were frequently expressed in RA synovial tissues, quantitative RT-PCR indicated that the mean expression level of MT1-MMP is approximately 11-fold higher than that of MT3-MMP. In contrast to a weak correlation of MT3-MMP mRNA expression with proMMP-2 activation, the expression of MT1-MMP in RA synovium correlated directly with the proMMP-2 activation ratio. Because the activator activity of MT3-MMP to proMMP-2 is much weaker than that of MT1-MMP (Ohuchi et al, 1997; Shimada et al, 1999), it is likely that MT1-MMP plays a major role in the activation of proMMP-2 in RA synovial tissue.

Recent studies have reported that the efficient pericellular activation of proMMP-2 by MT1-MMP requires the TIMP-2 molecule in the trimolecular complex formation of proMMP-2, TIMP-2, and MT1-MMP on cell membranes (Butler et al, 1998; Kinoshita et al, 1998). Our in situ hybridization study indicated a predominant mRNA expression of MT1-MMP in the hyperplastic lining cells of RA synovium. Protein expression in
RA synovial tissue was also demonstrated by immunobloting, and MT1-MMP was immunolocalized to RA synovial lining cells. This localization of MT1-MMP to the lining cells is further supported by the finding that the mRNA expression level of MT1-MMP correlated with the lining cell hyperplasia of RA synovium. In addition to the specific expression of MT1-MMP in synovial lining cells, both MMP-2 and TIMP-2 proteins were co-localized to the lining cells, suggesting a possible interaction of MT1-MMP, MMP-2, and TIMP-2 on the cell membranes of RA synovial lining cells.

Using in situ zymography, this study is the first to demonstrate gelatinolytic activity in the lining cell layer of RA synovium. This activity is ascribed to MMP because it was abolished by treatment with BB94, a hydroxamate MMP inhibitor. The distribution of MMP activity is in accordance with the localization of MT1MMP, MMP-2, and TIMP-2. Although gelatin is a non-specific substrate susceptible to many MMP, MMP-2, and MMP-9 are usually responsible for the activity because of their high specific activity to gelatin (Okada et al, 1990; Okada et al, 1992a). In our studies, gelatin zymography indicated that both proMMP-2 and proMMP-9 are produced in RA synovial tissue, but that the activated form of proMMP-9 is seldom found in both culture media and homogenates of RA synovium. This is in contrast to the frequent activation of proMMP-2. In addition, gelatinolytic activity was undetectable by in situ zymography in normal synovial tissue, which expressed negligible amounts of MT1MMP but produced some amount of proMMP-2. Collectively, these data suggest that the gelatinolytic activity in the RA synovial lining cell layer is ascribed mainly to MMP-2 activity generated by the action of MT1-MMP on the lining cell membranes.

MMP-2 plays an essential role in completing collagen degradation by digesting gelatins generated after the specific cleavage of collagen by collagenases (Okada, 2000). However, it can also digest other ECM components such as aggrecan, link protein, decorin, and fibronectin (Fosang et al, 1992; Imai et al, 1997a; 1997b; Nguyen et al, 1993; Okada et al, 1990). However, we (Ohuchi et al, 1997) and others (Pei and Weiss, 1996) have demonstrated that besides having an activator function for proMMP-2, MT1-MMP itself is active on ECM macromolecules, including fibrillar collagens, which are synergistically degraded by coincubation with MT1-MMP and active MMP-2 (Ohuchi et al, 1997). Thus, the proteolytic activities of MMP-2 and MT1-MMP produced in the RA synovial lining cell layer may contribute to the degradation of the cartilage ECM by direct contact of the synovium to the peripheral articular cartilage, which is initially degraded during the course of RA (Okada, 2000). Another possible function for the expression of these MMP may be that MMP-2, activated by MT1-MMP, is secreted from the lining cell layer into the synovial fluid and attacks the cartilage ECM from the surface. A low level of MT3-MMP was also expressed in RA synovial tissue. The function of this MT-MMP is not yet clear, but our recent studies demonstrate that recombinant 

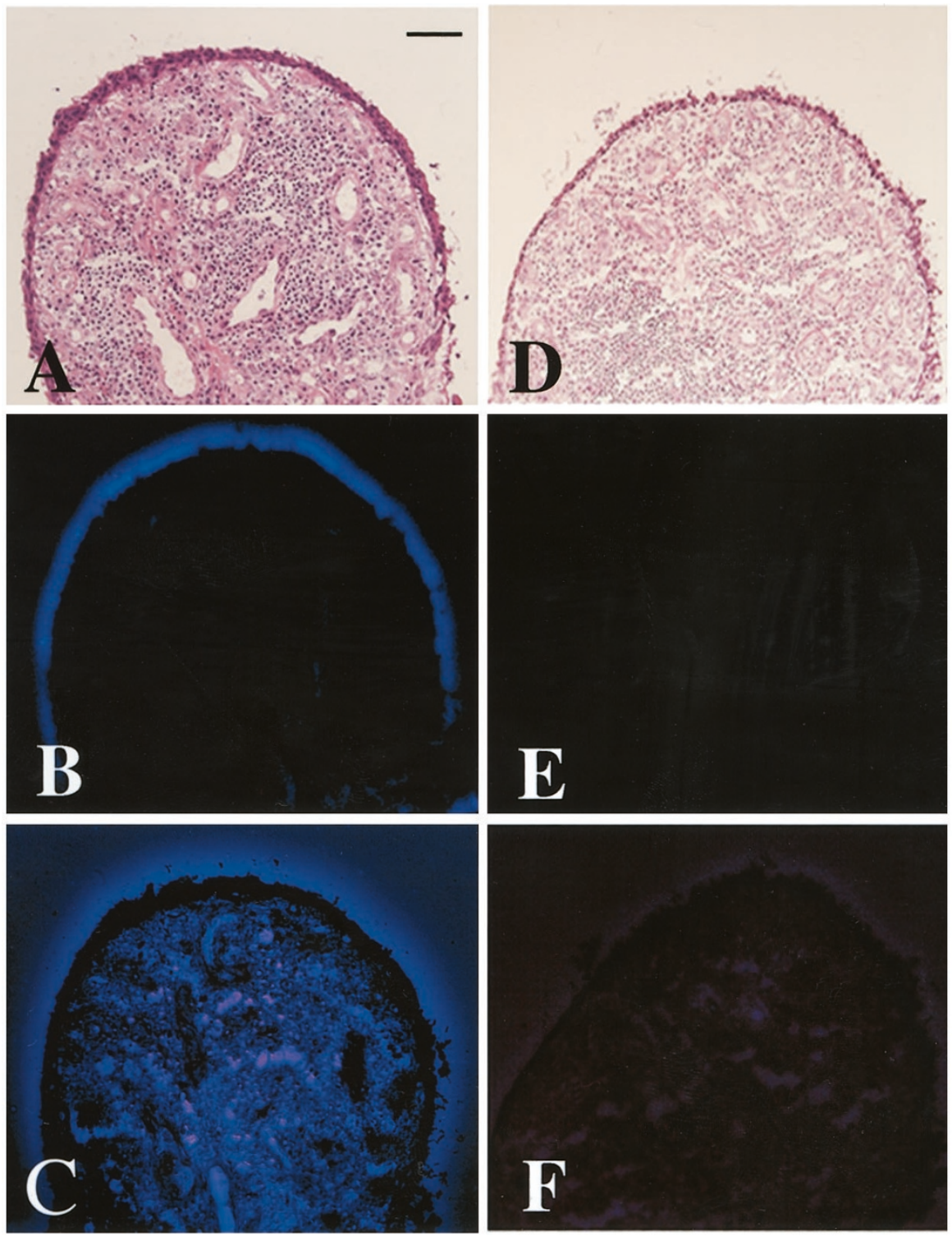

\section{Figure 8.}

In situ zymography of RA synovial tissue. Serial frozen sections of RA synovial tissue were stained with hematoxylin and eosin (A and D), or subjected to in situ zymography for 4 hours (B and E), or for 12 hours ( $C$ and F), as described in "Materials and Methods". Synovial tissue was treated with BB94 for 3 hours before the reaction for in situ zymography $(\mathrm{D}, \mathrm{E}$, and $\mathrm{F})$. Note the gelatinolytic activity, recognized by negative staining, in the lining cell layer (B) and in most areas of the synovium (C). Bar, $50 \mu \mathrm{m}$.

MT3-MMP can digest aggrecan as well as type III collagen, gelatin, and fibronectin (Shimada et al, 1999). The low but steady expression in RA and OA synovium suggests that MT3-MMP may also be involved in the turnover of the ECM components in the synovium.

\section{Materials and Methods}

\section{Clinical Samples and Histology}

Fresh human synovial tissues were obtained from patients with RA $(57.8 \pm 8.5$ years, mean age $\pm \mathrm{SD}$, $n=40)$ or OA (66.8 \pm 9.5 years, $n=29)$ patients who underwent arthroplasty surgery. RA and OA were diagnosed according to the 1987 revised American
Rheumatism Association criteria (Arnett et al, 1988) and the Classification of Osteoarthritis of the Knee (Altman et al, 1986), respectively. Normal synovial tissue without macroscopic or microscopic changes were obtained from patients undergoing femoral head replacement for femoral neck fractures $(73.5 \pm 6.9$ years, $n=11$ ).

Portions of the synovial samples were fixed for 18 to 24 hours at $4^{\circ} \mathrm{C}$ with periodate-lysine-paraformaldehyde or $4 \%$ paraformaldehyde for immunohistochemistry and in situ hybridization, respectively. Histological diagnosis was made by standard light-microscopic evaluation of the sections stained with hematoxylin and eosin. Synovial specimens were analyzed according to our previously reported grading system (Okada et 
al, 1992b). 1) Synovial lining cell hyperplasia was graded from 0 to $3+$. One to two layers of cells was graded as 0; three to four layers, 1+; five to six layers, $2+$; and seven or more layers, $3+$. Layers were counted from the surface of the membrane to the sublining cell layer. 2) Cellular infiltration (degree of infiltration by lymphocytes, and mononuclear and polymorphonuclear leukocytes) was graded from 0 to $4+$. No infiltration present was graded as 0 ; mild infiltration, 1+; moderate and focal infiltration, 2+; moderate and diffuse infiltration, $3+$; and marked and diffuse cellular infiltration, 4+. 3) Fibrosis of the sublining cell layer was graded from 0 to $3+$, where 0 was normal; $1+$, mild; $2+$, moderate; and $3+$, marked fibrosis.

\section{Preparation of Tissue Culture Media and Homogenates, and Sandwich Enzyme Immunoassay for MMP-2}

Synovial samples of RA (40 cases), OA (29 cases) and control normal synovial tissues (11 cases) were cut into small blocks (approximately $3 \times 3 \times 3 \mathrm{~mm}$ ), and cultured for 24 hours in $2 \mathrm{ml}$ of serum-free $\alpha$-minimum Eagle's medium containing $0.2 \%$ lactalbumin hydrolysate (GibcoBRL, Gaithersburg, Maryland) in a 5\% $\mathrm{CO}_{2}$ incubator. Culture media were stored at $-20^{\circ} \mathrm{C}$ until used, and tissue blocks were weighed after lyophilization. Tissue samples were homogenized on ice in $50 \mathrm{~mm}$ Tris- $\mathrm{HCl}$ buffer, $\mathrm{pH} 7.5$, containing $0.15 \mathrm{M}$ $\mathrm{NaCl}, 10 \mathrm{~mm} \mathrm{CaCl}_{2}, 0.02 \% \mathrm{NaN}_{3}$, and $0.05 \%$ Brij 35 . The homogenates were centrifuged at $4^{\circ} \mathrm{C}$ for 20 minutes at $10,000 \times \mathrm{g}$, and protein concentration in the supernatants was determined by the dye-binding method according to the manufacturer's instructions (Bio-Rad, Hercules, California). The concentration of MMP-2 in the media and supernatants was measured by the corresponding EIA system for MMP-2 as described previously (Fujimoto et al, 1993). The EIA system measures proMMP-2 and its complex form with TIMP-2 but not active MMP-2 species. The values, $\mathrm{nmol} / \mathrm{g}$ dry weight for culture media and $\mathrm{nmol} / \mathrm{g}$ protein for tissue homogenates, were determined by using the molecular weight of proMMP-2 derived from the amino acid sequence (Mr 70,930) (Nakamura et al, 1999).

\section{Gelatin Zymography}

Gelatinolytic activity in the culture media and tissue homogenates was examined by gelatin zymography. The culture media ( $1 \mu \mathrm{l} / \mathrm{mg}$ dry weight tissue) and the supernatants of homogenates $(20 \mu \mathrm{g}$ of protein per lane) were subjected to sodium dodecyl sulfatepolyacrylamide gel electrophoresis (SDS-PAGE) using $0.2 \%$ gelatin-containing gels as described previously (Nakamura et al, 1999; Nomura et al, 1996). The samples were incubated at $37^{\circ} \mathrm{C}$ for 30 minutes in SDS sample buffer without a reducing agent, and then electrophoresed on $9 \%$ polyacrylamide gels at $4^{\circ} \mathrm{C}$. After electrophoresis, gels were washed in $2.5 \%$ Triton $\mathrm{X}-100$ to remove the SDS; incubated for 22 hours at $37^{\circ} \mathrm{C}$ in $50 \mathrm{~mm}$ Tris- $\mathrm{HCl}, \mathrm{pH} 7.5$, containing $0.15 \mathrm{M}$
$\mathrm{NaCl}, 10 \mathrm{~mm} \mathrm{CaCl}_{2}$, and $0.02 \% \mathrm{NaN}_{3}$; and stained with $0.1 \%$ Coomassie brilliant blue R250. Ratios of proMMP-2 activation were estimated by computerassisted densitometric scanning of the 62-kd and 68-kd proteolytic bands, which correspond to the active and latent species of MMP-2, respectively.

\section{Quantitative RT-PCR}

Total RNA was isolated from RA (30 cases), OA (14 cases) and normal (8 cases) synovial specimens by ISOGEN (Nippon Gene, Toyama, Japan). The extracted RNA was treated with RNase-free DNase (Boehringer Mannheim, GmbH, Mannheim, Germany) to eliminate DNA contamination, and converted to single-stranded cDNA using a random oligonucleotide hexamer (Takara, Otsu, Japan). Randomly primed cDNAs were prepared from $5 \mu \mathrm{g}$ of total RNA by $M-M L V$ reverse transcriptase (GibcoBRL) followed by PCR amplification. Non-radioisotopic quantitative RTPCR was carried out according to previously published methods (Nakada et al, 1999). Briefly, cDNAs obtained from synovial specimens were amplified using specific primers for human MT1-MMP (forward primer: 5'-TCGGCCCAAAGCAGCAGCTTC-3', reverse primer: 5'-CTTCATGGTGTCTGCATCAGC-3'), MT2-MMP (forward primer: 5'-CAGCCCAGCCGCCATATGTC-3', reverse primer: 5'-CTTTCACTCGTACCCCGAAC-3'), MT3-MMP (forward primer: 5'ACAGTCTGCGGAACGGAGCAG-3', reverse primer: 5'-GTCAATTGTGTTTCTGTCCAC-3') and GAPDH (forward primer: 5'-CCACCCATGGCAAATTCCATGGCA-3' reverse primer: 5'-TCTAGACGGCAGGTCAGGTCCACC-3'). PCR conditions for the MT-MMP amplification were 20 to 36 cycles at 2-cycle intervals, at $94^{\circ} \mathrm{C}$ for 1 minute, $50^{\circ} \mathrm{C}$ for 1 minute, and $72^{\circ} \mathrm{C}$ for 1 minute, followed by incubation at $72^{\circ} \mathrm{C}$ for $3 \mathrm{~min}$ utes. The conditions for GAPDH amplification were the same as those for MT-MMP, except for 1 minute for annealing at $60^{\circ} \mathrm{C}$. The products were electrophoresed on $3 \%$ agarose gels including $0.1 \mu \mathrm{g} / \mathrm{ml}$ of ethidium bromide. The intensity of ethidium-bromide fluorescence was measured using a charge-coupled device imaging system (FAS II; TOYOBO, Tokyo, Japan) and Digital Image File Fujix DF-20 (Fuji Photo Film, Tokyo, Japan). The reaction cycle-PCR product of each reaction mixture was plotted on semilogarithmic graphs for each sample. Control curves were obtained by serial dilutions of MT-MMP and GAPDH plasmid cDNAs (Sato et al, 1994; Takino et al, 1995) and PCR was performed similarly to synovial specimens as previously described (Nakada et al, 1999). The sample concentration-PCR products of each reaction mixture were plotted on semilogarithmic graphs. To standardize gel staining conditions, a constant amount of control DNA marker (Promega, Madison, Wisconsin) was electrophoresed every time. The PCR procedure was performed at least three times for each sample.

When RT-PCR for MT-MMP and GAPDH was carried out using total RNA from synovial tissues by running 20 to 36 cycles at an interval of 2 cycles, the 
products emerged between 22 and 28 cycles, increased exponentially with cycles up to 32 to 34 , and then reached a plateau (not shown). Thus, PCR amplification was set at 30 cycles, and calibration lines for cDNA concentrations of MT-MMP and GAPDH were obtained using serial dilutions of plasmid cDNAs for MT-MMP and GAPDH (not shown). Fluorescence intensity of each PCR product was proportional to the amounts of cDNAs used as templates, and calibration lines obtained for cDNAs of MT-MMP and GAPDH were used for further calculation of MT-MMP/GAPDH cDNA molar ratios, which represent MT-MMP/GAPDH mRNA ratios (Nakada et al, 1999). We analyzed each sample at least three times by this method; the differences in the obtained values was less than $2 \%$.

\section{In Situ Hybridization}

To verify the origin of cells expressing MT1-MMP and MT3-MMP mRNA, RA samples (8 cases) which showed MT1-MMP and MT3-MMP expression by RT-PCR were used for in situ hybridization according to the methods previously described (Nakada et al, 1999; Okada et al, 1995). Briefly, the cDNA fragments encoding MT1-MMP nucleotides 2483 to 2884 (401 bp) and MT3-MMP nucleotides 649 to 849 (200 bp) were subcloned into Bluescript KS (Stratagene, La Jolla, California), and sense and antisense digoxigenin-labeled RNA probes were prepared with T3 or T7 RNA polymerase using DIG RNA Labeling Kit (Boehringer Mannheim). Paraffin sections of the tissues were hybridized with either antisense or sense RNA. After being washed under stringent conditions (2X SSC, 0.5X SSC, and 0.1X SSC, twice each for 30 minutes at $50^{\circ} \mathrm{C}$ ), the sections were incubated with a mouse monoclonal antibody to digoxingenin (Boehringer Mannheim), and the antibody bound to the antigen was complexed with biotinylated horse anti-(mouse lgG) lgG (Vector Laboratories, Burlingame, CA). Color was developed by the avidin-biotin-peroxidase complex method (DAKO, Glostrup, Denmark).

\section{Immunohistochemistry and Immunoblotting}

Monoclonal antibodies to MT1-MMP (clone 114-6G6), MMP-2 (clone 75-7F7) and TIMP-2 (clone 67-4H11) were previously characterized (Ueno et al, 1997; Fujimoto et al, 1993, 1995), and provided by Dr. Kazushi Iwata from Fuji Chemical Industries, Ltd. (Takaoka, Japan). The paraffin sections were reacted with antibodies to MT1-MMP (30 $\mu \mathrm{g} / \mathrm{ml})$, MMP-2 (2 $\mu \mathrm{g} / \mathrm{ml})$, TIMP-2 (1 $\mu \mathrm{g} / \mathrm{ml})$ or non-immune mouse lgG (30 $\mu \mathrm{g} / \mathrm{ml}$ ), and the color was developed by the avidin-biotin-peroxidase complex methods as described previously (Ueno et al, 1997; Nakamura et al, 1999; Nakada et al, 1999).

Supernatants of the homogenates (70 $\mu \mathrm{g} / \mathrm{lane})$ from RA (seven cases) and normal (three cases) synovial tissues were resolved by SDS-PAGE (10\% total acrylamide) under reducing conditions, and transferred onto nitrocellulose filters (Amersham International, Buckinghamshire, United Kingdom). The filters were reacted with $20 \mu \mathrm{g} / \mathrm{ml}$ of monoclonal antibody to
MT1-MMP (clone 114-6G6) or $20 \mu \mathrm{g} / \mathrm{ml}$ of nonimmune mouse IgG. Color was developed with the avidin-biotin-peroxidase complex method.

\section{In Situ Zymography}

Fresh specimens of RA and normal synovial tissues (10 and 3 cases, respectively) were embedded without fixation in Tissue-Tek OCT compound (Miles, Inc., Elkhart, Indiana). Serial frozen sections were made on a cryostat (MICROM, GmbH, Walldorf, Germany) and mounted onto either gelatin films that were coated with $7 \%$ gelatin solution (Fuji Photo Film Co. Ltd., Tokyo, Japan) or glass slides. The films with sections were incubated for up to 12 hours at $37^{\circ} \mathrm{C}$ in a humidified chamber, and stained with $1 \%$ Amido Black 10B (WAKO Junyaku, Osaka, Japan). Gelatin that was in contact with areas of the sections that harbored gelatinolytic activity was digested, thus identifying zones of enzymatic activity by negative staining. As a control, RA tissues were incubated in Dulbecco's modified Eagle's medium containing $0.2 \%$ lactalbumin hydrolysate with or without $50 \mu \mathrm{M}$ BB94 (British Biotech Pharmaceuticals, Oxford, England) for 3 hours at $37^{\circ} \mathrm{C}$, and the frozen sections were treated in a similar way as described above.

\section{Statistics}

Statistical analyses were performed using the chisquare test and the two-tailed Mann-Whitney $U$ test. $P$ values less than 0.05 were considered significant.

\section{Acknowledgements}

We are grateful to Dr. Kazushi Iwata (Fuji Chemical Industries, Ltd, Takaoka, Japan) for providing the monoclonal antibodies, and Dr. Kiran Chada (Department of Biochemistry, Robert Wood Johnson Medical School, University of Medicine and Dentistry of New Jersey, Piscataway, New Jersey) for reading the manuscript.

\section{References}

Altman RD, Asch E, Bloch D, Bole G, Bornstein D, Brandt K, Christy W, Cooke TD, Greenwald R, Hochberg M, Howell DS, Kaplan D, Koopman W, Longley S, Mankin HJ, McShane DJ, Medsger T Jr, Meenan R, Mikkelson W, Moskowitz R, Murphy W, Rothschild B, Segal M, Sokoloff L, and Wolfe F (1986). Development of criteria for the classification and reporting of osteoarthritis. Classification of osteoarthritis of the knee. Diagnostic and Therapeutic Criteria Committee of the American Rheumatism Association. Arthritis Rheum 29: 1039-1049.

Arnett FC, Edworthy SM, Block DA, McShane DJ, Freis JF, Cooper NS, Healey LA, Kaplan SR, Liang MH, Pinals RS, Schlaller JG, Sharp JT, Wilder RL, and Hunder GG (1988). The American Rheumatism Association 1987 revised criteria for the classification of rheumatoid arthritis. Arthritis Rheum 31:315-324.

Butler GS, Butler MJ, Atkinson SJ, Will H, Tamura T, Van Westrum SS, Crabbe T, Clements J, D'Ortho MP, and Murphy G (1998). The TIMP2 membrane type 1 metallopro- 
teinase "receptor" regulates the concentration and efficient activation of progelatinase A. A kinetic study. J Biol Chem 273:871-880.

Buttner FH, Chubinskaya S, Margerie D, Huch K, Flechtenmacher J, Cole AA, and Bartnik E (1997). Expression of membrane type 1 matrix metalloproteinase in human articular cartilage. Arthritis Rheum 40:704-709.

Fosang AJ, Neame PJ, Last K, Hardingham TE, Murphy G, and Hamilton JA (1992). The interglobular domain of cartilage aggrecan is cleaved by PUMP, gelatinases, and cathepsin B. J Biol Chem 267:19470-19474.

Fujimoto N, Mouri N, Iwata K, Ohuchi E, Okada Y, and Hayakawa T (1993). A one-step sandwich enzyme immunoassay for human matrix metalloproteinase 2 (72-kd gelatinase/type IV collagenase) using monoclonal antibodies. Clin Chim Acta 221:91-103.

Fujimoto N, Tokai H, Okada Y, and Hayakawa T (1995). Determination of tissue inhibitor of metalloproteinases-2 (TIMP-2) in experimental animals using monoclonal antibodies against TIMP-2-specific oligopeptides. J Immunol Methods 187:33-39.

Hembry RM, Bagga MR, Reynolds JJ, and Hamblen DL (1995). Immunolocalisation studies on six matrix metalloproteinases and their inhibitors, TIMP-1 and TIMP-2, in synovia from patients with osteo- and rheumatoid arthritis. Ann Rheum Dis 54:25-32.

Imai K, Hiramatsu A, Fukushima D, Pierschbacher MD, and Okada Y (1997a). Degradation of decorin by matrix metalloproteinases: Identification of the cleavage sites, kinetic analyses and transforming growth factor-beta 1 release. Biochem J 322:809-814.

Imai K, Ohta S, Matsumoto T, Fujimoto N, Sato H, Seiki M, and Okada $Y$ (1997b). Expression of membrane-type 1 matrix metalloproteinase and activation of progelatinase $A$ in human osteoarthritic cartilage. Am J Pathol 151:245-256.

Itoh $\mathrm{Y}$, Kajita M, Kinoh $\mathrm{H}$, Mori $\mathrm{H}$, Okada A, and Seiki M (1999). Membrane type 4 matrix metalloproteinase (MT4MMP, MMP-17) is a glycosylphosphatidylinositol-anchored proteinase. J Biol Chem 274:34260-34266.

Kinoshita T, Sato H, Okada A, Ohuchi E, Imai K, Okada Y, and Seiki M (1998). TIMP-2 promotes activation of progelatinase $A$ by membrane-type 1 matrix metalloproteinase immobilized on agarose beads. J Biol Chem 273:16098-16103.

Kolkenbrock H, Essers L, Ulbrich N, and Will H (1999). Biochemical characterization of the catalytic domain of membrane-type 4 matrix metalloproteinase. Biol Chem 380: 1103-1108.

Konttinen YT, Ceponis A, Takagi M, Ainola M, Sorsa T, Sutinen M, Salo T, Ma J, Santavirta S, and Seiki M (1998). New collagenolytic enzymes/cascade identified at the pannus-hard tissue junction in rheumatoid arthritis: Destruction from above. Matrix Biol 17:585-601.

Llano E, Pendás AM, Freiji JP, Nakano A, Knäuper V, Murphy G, and López-Otin C (1999). Identification and characterization of human MT5-MMP, a new membrane-bound activator of progelatinase $A$ overexpressed in brain tumors. Cancer Res 59:2570-2576.

Nagase H (1997). Activation mechanisms of matrix metalloproteinases. Biol Chem 378:151-160.

Nagase H and Woessner JF Jr (1993). Role of endogenous proteinases in the degradation of cartilage matrix. In: Woess- ner JF Jr and Howell DS, editors. Joint cartilage degradation. New York: Marcel Dekker, 159-185.

Nakada M, Nakamura H, Ikeda E, Fujimoto N, Yamashita J, Sato H, Seiki M, and Okada Y (1999). Expression and tissue localization of membrane-type 1, 2, and 3 matrix metalloproteinases in human astrocytic tumors. Am J Pathol 154: 417-428.

Nakamura H, Ueno H, Yamashita K, Shimada T, Yamamoto E, Noguchi M, Fujimoto N, Sato H, Seiki M, and Okada Y (1999). Enhanced production and activation of progelatinase A mediated by membrane-type 1 matrix metalloproteinase in human papillary thyroid carcinomas. Cancer Res 59:467473.

Nguyen Q, Murphy G, Hughes C, Mort JS, and Roughler PJ (1993). Matrix metalloproteinases cleave at two distinct sites on human cartilage link protein. Biochem J 295:595-598.

Nomura H, Fujimoto N, Seiki M, Mai M, and Okada Y (1996). Enhanced production of matrix metalloproteinases and activation of matrix metalloproteinase 2 (gelatinase A) in human gastric carcinomas. Int J Cancer 69:9-16.

Nomura H, Sato H, Seiki M, Mai M, and Okada Y (1995). Expression of membrane-type matrix metalloproteinase in human gastric carcinomas. Cancer Res 55:3263-3266.

Ohuchi E, Imai K, Fujii Y, Sato H, Seiki M, and Okada $Y$ (1997). Membrane type 1 matrix metalloproteinase digests interstitial collagens and other extracellular matrix macromolecules. J Biol Chem 272:2446-2451.

Okada, Y (In press, 2000). Proteinases and matrix degradation. In: Kelley WN, Harris ED Jr, Ruddy S, and Sledge CB, editors. Textbook of Rheumatology, 6th ed. Philadelphia: WB Saunders Co.

Okada Y, Gonoji Y, Naka K, Tomita K, Nakanishi I, Iwata K, Yamashita K, and Hayakawa T (1992a). Matrix metalloproteinase 9 (92-kd gelatinase/type IV collagenase) from HT 1080 human fibrosarcoma cells. Purification and activation of the precursor and enzymic properties. J Biol Chem 267: 21712-21719.

Okada Y, Morodomi T, Enghild JJ, Suzuki K, Yasui A, Nakanishi I, Salvesen G, and Nagase H (1990). Matrix metalloproteinase 2 from human rheumatoid synovial fibroblasts. Purification and activation of the precursor and enzymic properties. Eur J Biochem 194:721-730.

Okada Y, Naka K, Kawamura K, Matsumoto T, Nakanishi I, Fujimoto N, Sato H, and Seiki M (1995). Localization of matrix metalloproteinase 9 (92-kilodalton gelatinase/type IV collagenase gelatinase B) in osteoclasts: Implications for bone resorption. Lab Invest 72:311-322.

Okada Y, Shinmei M, Tanaka O, Naka K, Kimura A, Nakanishi I, Bayliss MT, Iwata K, and Nagase H (1992b). Localization of matrix metalloproteinase 3 (stromelysin) in osteoarthritic cartilage and synovium. Lab Invest 66:680-690.

Pei D (1999). Identification and characterization of the fifth membrane-type matrix metalloproteinase MT5-MMP. J Biol Chem 274:8925-8932.

Pei D and Weiss SJ (1996). Transmembrane-deletion mutants of the membrane-type matrix metalloproteinase-1 process progelatinase $A$ and express intrinsic matrix-degrading activity. J Biol Chem 271:9135-9140. 
Puente XS, Pendás AM, Llano E, Velasco G, and López-Otin C (1996). Molecular cloning of a novel membrane-type matrix metalloproteinase from a human breast carcinoma. Cancer Res 56:944-949.

Sato H, Takino T, Okada Y, Cao J, Shinagawa A, Yamamoto E, and Seiki M (1994). A matrix metalloproteinase expressed on the surface of invasive tumour cells. Nature 370:61-65.

Shimada T, Nakamura H, Ohuchi E, Fujii Y, Murakami Y, Sato $\mathrm{H}$, and Okada $Y$ (1999). Characterization of a truncated recombinant form of human membrane type 3 matrix metalloproteinase. Eur J Biochem 262:907-914.

Takino T, Sato H, Shinagawa A, and Seiki M (1995). Identification of the second membrane-type matrix metalloproteinase (MT-MMP-2) gene from a human placenta cDNA library. MT-MMP form a unique membrane-type subclass in the MMP family. J Biol Chem 270:23013-23020.

Tsunezuka Y, Kinoh H, Takino T, Watanabe $Y$, and Okada $Y$ (1996). Expression of membrane-type matrix metalloproteinase 1 (MT1-MMP) in tumor cells enhances pulmonary metastasis in an experimental metastasis assay. Cancer Res 56:5678-5683.
Ueno $\mathrm{H}$, Nakamura $\mathrm{H}$, Inoue M, Imai K, Noguchi M, Sato H, Seiki M, and Okada $Y$ (1997). Expression and tissue localization of membrane-types 1, 2, and 3 matrix metalloproteinases in human invasive breast carcinomas. Cancer Res 57:2055-20560.

Wang Y, Johnson AR, Ye QZ, and Dyer RD (1999). Catalytic activities and substrate specificity of the human membrane type 4 matrix metalloproteinase catalytic domain. J Biol Chem 274:33043-33049.

Will $\mathrm{H}$ and Hinzmann B (1995). cDNA sequence and mRNA tissue distribution of a novel human matrix metalloproteinase with a potential transmembrane segment. Eur $\mathrm{J}$ Biochem 231:602-608. 